\title{
Using the Cultureme Paradigm in FLT
}

\author{
Alenka Kocbek \\ Faculty of Education, University of Primorska, Slovenia \\ alenka.kocbek@pef.upr.si
}

In contemporary foreign language teaching one of the main objectives pursued is to enable foreign language learners to use the language skills developed in the learning and acquisition process to effectively communicate across language and cultural barriers. In doing this, foreign language users often resort to strategies which have been systematically researched and developed in the sphere of translation studies. We thus suggest applying the cultureme paradigm, which was originally designed to be used in translator training (Oksaar 1988; Kocbek 2013), as a scaffolding tool supporting FL learners in developing a fully-fledged communicative competence involving verbal, paraverbal, non-verbal and extra-verbal aspects, to be used in multilingual settings.

Keywords: foreign language teaching, translation, text-cultureme, memetic structure

\section{Introduction}

If we listen to the students' communication in most of the schools in Europe, we hear a number of languages and codes, and, when closely examining their interactions, we find out that students do not only switch between linguistic codes, but also spontaneously use a number of strategies which originally belong to the sphere of interpreting and translation studies. Thus, this situation very explicitly mirrors the linguistic landscape of contemporary Europe, described by Umberto Eco, in his lecture delivered at the Assises de la Traduction littéraire in Arles, in November 1993, in his famous quote 'The language of Europe is translation.' This statement reflects the ubiquitous situation in which people use languages other than their mother tongue to communicate on a daily basis and the fact that translation has become one of the main assets of daily communication in multilingual settings. It also stresses the importance of translation skills as an essential means for enabling effective communication among EU citizens and across language and cultural barriers in general. With the intensification of the migration flows in the last decades, but also traditionally in bi- and multilingual regions, more and more people find themselves in situations which require some amount of translation and/or interpreting in order to enable communication. Often the very exercise of fundamental human rights (e.g. access to medical services, to legal protection, education, etc.) can depend on a person's ability to use 
a (foreign) language and/or on the availability of translation. Therefore, foreign language users occasionally act as 'natural translators' (Nord 1991) in situations where professional translation or interpreting is not available. This phenomenon, termed as language brokering is actually one of the most recent facets of pluriculturality and plurilingualism. What we are facing today is a drastic increase in the amount of professional translation and interpreting globally, but also a giant wave of non-professional translating and interpreting gaining momentum worldwide in all walks of life as a consequence of the increased mobility of the world population and the persisting migration flows. If education is to respond to the real needs of contemporary society, these developments need to be systematically acknowledged by the policies and practice of foreign language teaching (FLT). In the area of language teaching the last decades have witnessed the flourishing of the communicative approach as the prevalent teaching method, which stresses the importance of the communicative competence to be developed by FL learners by engaging in meaningful communication, hence one of the primary goals of FLT should be enabling the students to effectively engage in communication by using the foreign languages learned, but also the whole linguistic repertoire at their disposal. ${ }^{1}$

Somehow contradictorily, the communicative approach did not promote developing translation skills, as this would have implied acknowledging the learners' mother tongues, as well as the whole spectrum of languages present in the learners' environment. Several authors have thus advocated that translation is an essential component of the communicative competence (Vermes 2010; Cook 2010; Bratož and Kocbek 2013). Some scholars in the last decades actually argued that translation needed to be considered as the fifth language skill, along with the four traditional language skills (Naimushin 2002; Newmark 1991). Following these developments the so-called pedagogical translation, i.e. translation used as a tool and technique for effective language teaching, has found its way back into language curricula after years of having being banished from language classrooms. Eventually, also the Companion Volume to the Common European Framework of Reference for Languages (CEFR) published in 2018, grants considerably more attention and importance to mediation activities (Council of Europe 2018, 105) compared to the first edition of the CEFR published in 2001 (Council of Europe 2001). Interlingual and intercultural mediation occur by using translation and interpreting, hence the Companion Volume to the CEFR stresses the need to

\footnotetext{
${ }^{1}$ For the purpose of this chapter no distinction will be made between second and foreign language teaching and the term foreign language teaching (FLT) will be used to refer to both.
} 
systematically address these aspects in language teaching practices. But as there seems to be less and less doubt as to the legitimacy of pedagogical translation being included into language curricula, we want to argue that translation studies as a discipline have more to offer to language teaching than the mere practice of translation and/or interpreting. In their recent history, translation studies, especially the approaches marking the so-called cultural turn (Snell-Hornby 1988), developed several approaches and strategies which stress the essential interrelatedness and interdependence of language and culture, while the functionalist theories stressed the necessity of adapting translation to the intended communicative purpose (Nord 1997), which often means adapting it to the prospective receiver. These approaches are aimed at optimizing communication across language and cultural barriers by paying due attention to elements of culture which are specific or unique to a specific culture, i.e. have the status of memes according to Chesterman (1997) and which, in order to be made accessible to members of a different culture, require special translation approaches. This memetic transfer is of utmost importance especially in specialized settings, where a misrendering of the original concept could prevent effective communication causing serious consequences (such as e.g. in legal or medical communication), thus translation strategies and models have been designed which are aimed at envisaging all dimensions shaping a communicative act. To this purpose a translation model for legal translation based on the concept of cultureme as proposed by Els Oksaar in her cultureme-theory (1988), but elaborated and upgraded by taking into account the multifaceted aspects of communication, was designed and has been used in training translation students, as well as practising legal translators and interpreters (Kocbek 2014a).

We suggest applying the cultureme paradigm to language teaching and using it as a scaffolding tool to systematically address all aspects involved in communication, i.e. its verbal, para-verbal, non-verbal and extra-verbal elements, thus raising the awareness of language learners to how language use is conditioned by culture in the broadest sense and by the communicative purpose pursued. In line with this view, FL learners need to grasp that to effectively use a language in multicultural settings one needs to consider the cultures involved (i.e. in FLT the culture underlying a student's mother tongue and the $\mathrm{FL}$, but also other cultures underlying the students' linguistic repertories).

\section{Spoken and Written Texts as Culturemes}

In light of Oksaar's cultureme theory, when observing communicative situations, we can identify patterns of communicative behaviour, i.e. culturemes 


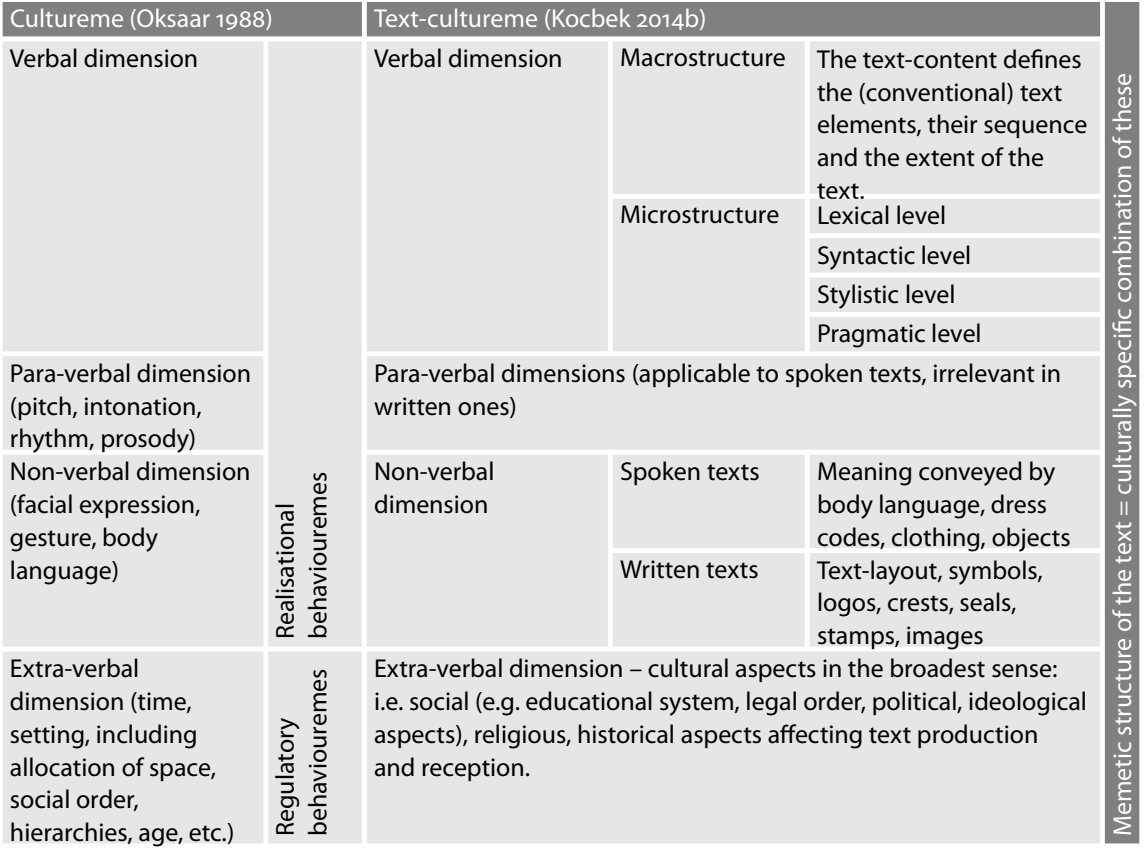

Figure 1 Comparison of Oksaar's Cultureme and Kocbek's Text-Cultureme Paradigm

(1988). Oksaar defines culturemes as socio-cultural categories, realised through realisational and regulatory 'behaviouremes.' 'Realisational behaviouremes' refer to verbal (choice of linguistic means), para-verbal (intonation, pitch, tone, prosody) and non-verbal (e.g. gestures, body language) aspects of a communicative act, while 'regulatory' ones involve extra-linguistic factors, such as time, space, status, social order, etc. (Oksaar 1988, 26-7). As shown by Kocbek (2014b), the cultureme paradigm can be applied to spoken, as well as to written texts, which have been termed text-culturemes. In order to fully exploit the cultureme paradigm as a scaffolding tool, we have further structured it into several dimensions to accommodate the multiple aspects of spoken and written texts viewed as culturally-specific patterns of spoken and written communicative behaviour, both in the process of text reception and/or production.

When teaching a language with the aim to prepare students to be able to successfully engage in communication, students' attention should be directed to notice aspects of culturally-conditioned patterns of spoken and written communicative behaviour (culturemes) and compare them with the corresponding communicative patterns in their native culture by adopting 
a contrastive perspective, i.e. by identifying similarities and differences on the different text-levels. In this way, they will be able to map the memetic structure of a text, created through the unique interplay of the verbal, paraverbal, non-verbal and extra-verbal dimension. They should then be made acquainted with the translation strategies best suiting different communicative purposes, which will enable them to apply the cultureme-paradigm both in text reception and production in a targeted way. Taking into account the memetic structure of texts will enable positive transfer and prevent the risk of negative transfer between their mother tongue and the FL (but also with respect to other languages forming their linguistic repertoire).

\section{The Verbal Dimension: Text Macro- and Microstructure}

The most obvious and relevant text dimension in terms of language teaching is the verbal one, i.e. the use of linguistic means by the agents involved in the communication. Within the text-cultureme paradigm we propose splitting the verbal dimension into the text macrostructure and microstructure.

Macrostructure refers to the text elements necessary to convey the intended text content and the sequence in which they appear in the text. This dimension is more evident in written texts, where the conventional text elements of a given genre are structured into a more or less rigid text template, such as for example the standard elements used in formal letters, e.g. indicating the sender, receiver, date, reference line, salutation, body of the letter, complimentary closes and the signature block. A similar sequence of elements can be found in relatively simple genres such as recipes, with the list of the ingredients, information regarding the number of servings, instructions for the preparation process, but also in more complex ones, such as academic papers, where norms and conventions regarding the text macrostructure are considered binding and ignoring them may result in a paper being rejected by reviewers. In legal texts, for instance, the standard elements of a text, especially of an agreement or contract are referred to as boilerplate elements and differ considerably between legal cultures as a consequence of different legal norms applying to contract law in the major legal systems.

The text microstructure, on the other hand, refers to the use of lexical items (i.e. the vocabulary used to realize a specific communicative pattern in the form of a spoken or written text), as well as to combining these items into more or less standardized syntactic structures, i.e. sentences, which shape the syntactic dimensions of the text. In spoken communication sentences are often shorter, even truncated, compared to the ones used in written texts. The specific usage of the vocabulary (i.e. of a given language register) and 
the complexity of the syntactic structures shape the stylistic dimension of the text, giving it a more or less formal character. Finally, the combined use of the lexical, syntactic and stylistic features enables language users to realize the intended pragmatic function of the text (e.g. requesting, advising, ordering, explaining, granting permission, assuming obligations, etc.).

On the lexical level of the text, language users may have to deal with concepts, ideas, cultural practices, which only exist in a specific culture, i.e. have the status of memes according to Chesterman (1997) and can only be transferred across language and cultural barriers by using translation. In this context, translation should be intended as the use of a targeted translational strategy which best suits the communicative purpose pursued. For example, when translating a formal letter drafted in the source culture, intended to be used in a target culture, the text macro- and microstructure will be adapted to comply with the established text-cultureme in the target culture. This will imply adapting the salutation, complimentary closes, etc. to the target culture norms by applying the so-called domestication strategy (Venuti 1995).

Applying the domestication strategy in recipes will imply, for instance, changing the measurements when translating them from/into English (pints to grams, pounds, litres etc.), or even substituting some ingredients, which are banned due to religious norms (e.g. rules on kosher or halal food), with culturally acceptable ones (e.g. substituting pork meat in a recipe intended for Jewish or Muslim users with other types of meat, or some exotic spice with a more accessible one).

Another possible translation strategy used when transferring memes is explicitation (Blum-Kulka 2004), which implies paraphrasing or explaining the target culture concept, which may have been implicit in the source text, in such a way that it is explicit and understandable to source culture receivers. In recipes, this would imply describing culturally-specific elements, e.g. ingredients (e.g. hummus - paste or spread made from ground chickpeas and sesame seeds, olive oil, lemon, and garlic) or utensils (e.g. wok - a bowlshaped frying pan, typically used in Chinese cuisine).

One of the ways of transferring memes is also rendering them with loan words (i.e. introducing the original term into the target culture, either unchanged or sometimes by adapting the spelling. i.e. the English muffin termed mafin in Slovene). This practice is widely accepted in translating recipes, especially when terms are transferred from cultures, whose culinary arts are highly valued (e.g. French terms such as souffé, meringue; or Italian words such as lasagna, focaccia, minestrone). This type of memetic transfer sometimes leads to new terms of foreign origin being incorporated into the 
target language, a process referred to as secondary term formation (Sager 1990,80 ). This was the case with many above mentioned culinary terms, e.g. words such as 'mixer', but also terms such as e.g. 'manager' and 'controlling' in business terminology, which are now used in Slovene with adapted spelling, i.e. mikser, menedžer, kontroling.

A further possibility of transferring memes is building calques. This has been a very frequent strategy in translating IT terminology from English into other languages, where for example 'downloading' was rendered in Italian with scaricare, and 'uploading' in Slovene with naložiti, both terms implying the reference to a physical load.

Loanwords and calques are often used as means for implementing the socalled foreignization approach (Venuti 1995), where target culture receivers are expected to become acquainted with memes of the source culture, which they would originally consider alien to their culture. This approach is often used when transferring memes from a culture perceived as superior, often economically and/or politically more powerful, into a target culture which is considered less influential. However, in everyday communication, language users sometimes need to resort to the foreignization strategy when they want to transfer memes of their native culture into a target language/culture irrespective of their status. Such memes may refer to culturally specific phenomena, ideas, cultural practices, such as e.g. celebrating festivities, but also to mythological creatures, elements of folklore, music, architecture, historical events or even linguistic features, such as for example the Slovene dual. In all these cases, FL learners should be made aware of available translation strategies which will enable them to use translation as the vehicle for bridging knowledge gaps between members of different cultures and as a powerful means of expanding cultural horizons.

\section{The Para-Verbal Dimension of Texts}

The para-verbal dimension involves the specific use of the voice, used to convey implicit and explicit shades of meaning by using intonation, pitch and prosody in a culturally-specific way (e.g. emotions such as joy, anger, but also highlighting important parts of utterances, showing respect by lowering the tone of one's voice), while also taking into consideration the relationship and/or hierarchical status of the communicating agents and the communicative purposes pursued by them. These dimensions also enable expressing features such as humour, irony, sarcasm, etc., merely by using one's voice in a targeted way. The para-verbal aspect can be culturally conditioned, i.e. spoken communication in some cultures is typically louder (e.g. Mediterranean 
countries) or using a higher pitch than in others. Learners of a FL should be made aware of the differences in the para-verbal dimension of spoken communication to avoid automatically und uncritically transferring the paraverbal features typically used in their native language to a foreign language.

\section{The Non-Verbal Dimension of Texts}

The non-verbal aspect is a further aspect essential to communication, as it can convey significant information supporting, often also determining the verbal and para-verbal dimension of the communication. As regards the nonverbal and extra-verbal dimensions of communication we have upgraded the cultureme model by adopting some of the views proposed by Balboni in his work Le sfide di Babele (2002), in which he describes the norms and conventions ruling these aspects of communication as special 'grammars.'

In spoken communication the non-verbal dimensions involves 'reading' and using facial expressions, gestures and body language, such as for example waving, beckoning, flagging, hushing, nodding (which are often specific to a given culture or may convey differing messages and can thus produce unplanned or undesired effects if uncritically transferred from one culture to the other). Oksaar (1988) suggests categorising these non-verbal communicative codes into three categories, i.e. so-called emblems (e.g. handclapping to express approval or praise), illustrators, which usually accompany verbal codes (e.g. the hand gesture used to accompany inviting somebody to sit down) and regulators (gestures used to require stopping, accelerating, slowing down). They may all carry different meanings as to the cultures in which they are used and Balboni refers to the capacity of mastering these differences by using the term competenza cinesica.

A further element of the non-verbal sphere is represented by the culturallyspecific use of clothing (termed competenza vestemica by Balboni), i.e. complying with dress-codes (e.g. wearing black or dark clothes when attending a funeral in Western cultures). Moreover, it involves identifying the function, professional status and authority conveyed by uniforms or special attires and even wigs (e.g. being able to distinguish between a police officer and a security guard, a nurse and a physician, a judge and a barrister in court, recognizing a religious minister).

This dimension of the communicative act can also involve deciphering and taking into account the identifying force of certain objects (which is referred to as competenza oggettuale by Balboni), such as national, political, religious symbols, but also paraphernalia indicating the role and status of a person, (e.g. a judge's gavel, the lawyers' robes, both indicating their judicial author- 
ity), and in general the tools of the trade typical of certain professions (e.g. a stethoscope used by a medical doctor). This aspect can also involve noticing and taking into consideration badges and tags indicating the belonging to different organisations and bodies (e.g. political, humanitarian, etc.). Mastering these different grammars will inform the overall communication with bearers of such non-verbal signs, especially the verbal and para-verbal dimension.

In written communication, the non-verbal dimension is realised through paratextual aspects, such as the text layout, use of logos, symbols, illustrations, tables, charts and typographic features (CEFR 2001, 80). The targeted use of some of these elements, such as logos and symbols identifying companies, organisations and various bodies, seals and stamps, but also photos and images may confer additional power to the verbal dimensions of texts such as formal letters, certificates, but also brochures and advertisements. For example, Slovene legal texts such as rulings or court orders have a special letterhead featuring the Slovene crest and usually bear the stamp of the institution issuing the document with the Slovene crest in its centre, which both underline the official character and authority of the text. Similarly, proficiency certificates and diplomas usually feature the crest and the official stamp or seal of the educational institution issuing them, or even contain a watermark to prevent potential misuse. Even a relatively pragmatic document, such as the extract from the company register often used in business communication, may bear extremely solemn traits and symbols. In the UK, for example, the certificate issued by the Companies House, which is equivalent to a Slovene or German extract from the company register, bears the royal coat of arms of the UK, with the motto of the English monarchs (i.e. Dieu at moin droit/'God and my Right') and of the Order of the Garter (i.e. Honi soit qui mal y pense/'Shame on him who thinks evil') in French. In comparison, the functionally equivalent certificates issued by the Agency of the Republic of Slovenia for Public Legal Records and Related Services (AJPES) or by the German company register (Unternehmensregister) look indisputably plain and simple, although they fulfil the same communicative purpose.

Often less official texts also make use of images to underline and support the communicative purpose of the text. In this respect it needs to be mentioned, however, that also the use of visual features is culture-bound, as well as that some symbols will be correctly understood and interpreted only by drawing on broader cultural knowledge, which may be lacking in case that the visual features of a text are uncritically transferred from one culture into another. These visual elements actually form a kind of (often culturally- 
conditioned) specialised visual grammar (cf. Kress and van Leeuwen 1996), which underlies and complements the verbal dimension of texts and needs to be learned and understood for effective communication to take place.

\section{The Extra-Verbal Dimension of Texts}

A further significant aspect of the text-cultureme is its extra-verbal dimensions. In her cultureme-theory Oksaar (1988) proposes to observe and take into account the impact of factors such as time, space, social variables, including age, gender, status, etc., on the realisation of a communicative act. Time will, for instance, define the type of greeting used in the course of a day or the conventional phrases used for season's greeting and wishes on occasion of holidays and festivities.

Space intended as the setting of a communicative act will also define the communication mode and the language register used in different ways. Communication in court, for instance, requires using the verbal mode only (non-verbal signs are not allowed/considered). In a classroom, too, the allocation of space between the teacher and the students will mark their roles and define their verbal and para-verbal communication. For example, it will require specific forms of address to be used by the communicating parties (e.g. addressing the teacher with Miss, Ms. or Mister and surname in English at primary level, and by using the word učitelj/-ica, or maestro/maestra only, in Slovene and Italian in corresponding settings). Similarly, communicating in a medical environment will require first identifying the different professionals (often through non-verbal codes such as the colour of the uniform) and then addressing them accordingly (e.g. addressing the physician with the word doktor in Slovene, while in English the common form of address will be Dr. followed by the surname) and the female nurse with the word sestra, i.e. 'sister,' which is mainly used with the same meaning in British English along with the term 'nurse.'

In most cultures, the age and status of the communicating parties will define the use of the verbal means to express respect, politeness, etc., either with grammatical means, i.e. by using the T-V distinction in Slovene, du/Sie in German, tu/Lei or Voi in Italian, or by other means, e.g. using specific forms of address in English, In some languages, such as Slovene, gender will be clearly expressed with corresponding morphological markers. In FLT, language users thus have to be made aware of the existence or lack of such gender specific expressions in different languages and taught strategies which will enable them to convey these aspects by other linguistic means (e.g. in English by using pronouns to refer to gender). In written communication gender will 
need to be considered for example in the salutations used in formal letters, where the English formula 'Dear Sir/Madam' will be rendered in Slovene with Spoštovani, whereas in Italian gender-specific formulations will be used, e.g. Egregio Signore for men and Gentile Signora, when addressing women.

In our text-cultureme paradigm, we suggest expanding the view from these somehow more immediately recognisable extra-verbal aspects to also include less obvious cultural aspects, which may inform communication in less explicit ways. These aspects include religious aspects and historical circumstances, which might have affected individual cultures in different ways, as well as the social order with its political and ideological implications. In many languages, religion permeates the greeting formulas, which contain a more or less recognizable reference to God, although very often native speakers of these languages do not normally make a conscious link with God when using them (e.g. the Slovene, slightly formal word for saying goodbye, zbogom, or the Italian addio, the Austrian and South German formula Grüß Gott, or the informal Croatian greeting 'bok' or 'bog' as an equivalent of 'Hil'). A political regime may also impose certain forms of address and greetings, as was the case in ex-Yugoslavia, where in Slovene adults were generally addressed with tovariš/-ica (i.e. comrade), sometimes followed by the name, surname or function. These forms of address were also used in correspondence, where even the typical complimentary close was derived from the word tovariš - official letters usually ended with the formula $S$ tovariškimi pozdravi! ('With comradely greetings').

These religious and ideological dimensions are often deeply intertwined with historical aspects, but also define the non-verbal dimension of communication (e.g. the official or prevailing religion indicated by religious symbols in classrooms in certain countries, images of political leaders exhibited in public spaces as an expression of the often totalitarian regime). The linguistic expressions of these aspects are often used automatically by native speakers, and they often survive historical changes and persist in language use even when social circumstances have changed. In Slovene, for example, the informal abbreviated form of tovarišica (female comrade), i.e. šica was used colloquially by children to address female preschool or lower-grade primary school teachers even some time after the Yugoslav socialist regime, to which these expressions pertained, was abolished. Similarly, the terms cesar and cesarski, i.e. 'emperor, imperial' are still sometimes used in Slovene to specifically refer to the Austrian-Hungarian emperor/court. Examples of this implied meaning are the name of a well know Slovene and Austrian dessert called cesarski praženec (German Kaiserschmarrn), supposedly creat- 
ed for the Austrian-Hungarian emperor Franz Joseph I, or describing somebody's polite manners by referring to them as 'Viennese-school', where both expressions originate in the period when most of what is now Slovene territory was part of the Austrian-Hungarian empire, ruled by the emperor and with the imperial court located in Vienna.

Historical circumstances may sometimes be reflected in the language use of individual cultures very differently. For instance, when referring to one of the crucial battles of the WW1 fought in the Soča/Isonzo valley in Slovenia in the vicinity of the town Kobarid (German Karfreit, Italian Caporetto), German sources usually use the term Wundervon Karfreit to describe the wonder, i.e. victory of the Austrian forces, whereas from the Italian point of view the same event is seen as a catastrophe and accordingly, the term caporetto (with lowercase spelling) has been included in the Italian vocabulary to refer to a defeat or catastrophe.

As we have shown above, language users who in the process of learning a FL will be made aware of the full communicative potential of spoken and written texts by drawing on their verbal, para-verbal, non-verbal and extraverbal dimensions, will also develop a contrastive perspective, i.e. they will be able to identify similarities and differences in the various dimensions of texts used for similar communicative purposes in their mother tongue and in other languages of their linguistic repertoire. This awareness will enhance their language sensitivity and help them exploit the full communicative potential of spoken and written texts.

\section{Conclusion}

By proposing the cultureme paradigm as a scaffolding tool to be used in language teaching we actually want to raise the learners' awareness of the fact that the combination of the verbal, para-verbal, non-verbal and extra-verbal elements involved in a spoken or written text used in communication represents a unique cultural practice, i.e. a complex meme. We therefore suggest analysing texts in the light of their memetic structure, both in the production, as well as in the reception phase. Acknowledging cultural differences not only at the verbal level, but also in other dimensions of the text culturemes, will help FL learners to develop their language skills, as well as to upgrade their sociolinguistic competence, which is essential for enabling effective crosscultural communication (CEFR Companion Volume 2018, 137 ss.). In her cultureme theory, Oksaar pointed out that the better one masters the verbal dimension of a foreign language, the higher the expectations of one's communication partners are with respect to his/her competence in understand- 
ing and drawing on the para-verbal, non-verbal and extra-verbal dimensions of communication.

In this respect, Eva Hoffman, a writer born in Poland, but who has spent most of her adult life in English speaking countries and has chosen English as the language of her artistic expression, in her autobiographical novel Lost in Translation: A Life in a New Language (1998) beautifully describes the frustration and helplessness felt by a non-native speaker using a foreign language, which derive from the fact that, although a language can be mastered almost to perfection in its verbal dimension, its full non-verbal and extra-verbal potential are never fully accessible to a non-native speaker. On the other hand, she shows with equal force and credibility that the position of an outsider in terms of language use enables an attentive non-native speaker to develop an awareness of and sensitivity for the most subtle features of language use, which often remain unnoticed by less perceptive native speakers of the same language, who use the language automatically, without being wholly aware of its expressive force and often without fully exploiting its immense potentialities.

\section{References}

Balboni, Paolo. 2002. Le sfide di Babele: Insegnare lingue nelle società complesse. Torino: UTET.

Blum-Kulka, Shoshana. 1986. 'Shifts of Cohesion and Coherence in Translation.' In Interlingual and Intercultural Communication: Discourse and Cognition in Translation and Second Language Acquisition Studies, edited by Juliana House and Shoshana Blum-Kulka, 17-35. Tübingen: Narr.

Bratož, Silva, and Alenka Kocbek. 2013. 'Resurrecting Translation in SLT: A Focus on Young Learners.' In Translation in Language Teaching and Assessment, edited by Dina Tsagari and Georgios Floros, 135-53. Newcastle upon Tyne: Cambridge Scholars.

Chesterman, Andrew. 1997. Memes of Translation. Amsterdam: John Benjamins.

Cook, Guy. 2010. Translation in Language Teaching. Oxford: Oxford University Press.

Council of Europe. 2001. Common European Framework of Reference for Languages: Learning, Teaching, Assessment. Strasbourg: Council of Europe.

- 2018. Common European Framework of Reference for Languages: Learning, Teaching, Assessment; Companion Volume with New Descriptors. Strasbourg: Council of Europe.

Hoffmann, Eva. 1998. Lost in Translation: A Life in a New Language. London: Vintage Books.

Kocbek, Alenka. 2013. 'Translation Science as an Aid to Second Language Teaching.' In Teaching, Acquiring and Applying Inter-Cultural Linguistic Com- 
petence, edited by Azamat Akbarov and Diane Larsen-Freeman, 63-72. Sarajevo: International Burch University.

- 2014a. 'The Translation of Legal Texts as Culturemes.' In Dynamics and Terminology, edited by Rita Temmerman and Marc Van Campenhoudt, 11134. Amsterdam: John Benjamins.

- 2014b. 'Unlocking the Potential of Translation for FLT.' Linguistica 54 (1): 425-38.

Kress, Gunther, and Theo van Leeuven. 1996. Reading Images: The Grammar of Visual Design. London: Routledge.

Naimushin, Boris. 2002. 'Translation in Foreign Language Teaching: The Fifth Skill.' Modern English Teacher 11 (4): 46-9.

Newmark, Peter. 1991. Approaches to Translation. Oxford: Pergamon Press.

Nord, Christiane. 1991. Text Analysis in Translation. Amsterdam: Rodopi. . 1997. Translating as a Purposeful Activity: Functionalist Approaches Explained. Manchester: St. Jerome.

Oksaar, Els. 1988. Kulturemtheorie: Ein Beitrag zur Sprachverwendungsforschung. Göttingen: Vandenhoeck u. Ruprecht; Hamburg: Joachim Jungius Gesellschaft der Wissenschaften.

Sager, Juan C. 1990. A Practical Course in Terminology Processing. Amsterdam: John Benjamins.

Snell-Hornby, Mary. 1988. Translation Studies: An Integrated Approach. Amsterdam: John Benjamins.

Venuti, Lawrence. 1995. The Translator's Invisibility. New York: Routledge.

Vermes, Albert. 2010. 'Translation in Foreign Language Teaching: A Brief Overview of Pros and Cons.' Eger Journal of English Studies 10:83-93. 